\title{
Multi-criteria decision-making for the life cycle of sustainable high pressure die casting products
}

\section{Emanuele Pagone*, Michail Papanikolaou, Konstantinos Salonitis and Mark Jolly}

\author{
Sustainable Manufacturing Systems Centre, \\ School of Aerospace, Transport and Manufacturing, \\ Cranfield University, \\ Cranfield, Bedfordshire, MK43 0AL, United Kingdom \\ E-mail: e.pagone@cranfield.ac.uk \\ E-mail: m.papanikolaou@cranfield.ac.uk \\ E-mail: k.salonitis@cranfield.ac.uk \\ E-mail: m.r.jolly@cranfield.ac.uk \\ *Corresponding author
}

\begin{abstract}
Although a significant body of literature has been devoted to establish metrics capable of measuring the performance of manufacturing systems (including foundries) and their influence on decision-making, there is a scarcity of comprehensive and organic studies on performance indicators encompassing sustainability. The objective of this investigation is the selection of the most suitable material for the manufacture of an automotive component using the High Pressure Die Casting (HPDC) process. The performance of three different alloys (Aluminium-A380, Magnesium-AZ91D and ZincZA8) was evaluated based on four different classes of metrics, namely: (a) cost, (b) time, (c) quality and (d) sustainability. The metrics selected refer to the overall product life cycle and process characteristics and have been normalised by mass to extend the applicability of the selection method to parts produced with similar process and design specifications but different mass. The deterministic TOPSIS method has been adopted to weigh and combine the different metrics used and drive the decision making process. According to the results, although the zinc alloy appears to be the most expensive option, it should be favoured over the two alternatives due to its significantly superior performance with respect to the quality and sustainability criteria. The current investigation demonstrates that the implementation of the TOPSIS method in combination with the added sustainability dimension influences the decision making process and challenges well-established decision making trends in the automotive industry during the past few decades.
\end{abstract}

Keywords: High Pressure Die Casting (HPDC); sustainable development; Multi Criteria Decision Making (MCDM); lifecycle analysis; manufacturing systems; foundries; material selection; sustainability metrics; Key Performance Indicators (KPIs); automotive products.

Biographical notes: Emanuele Pagone is Research Fellow in Sustainable Manufacturing Modelling at Cranfield University, UK. He received his BSc in Mechanical Engineering from the Polytechnic University of Bari and was awarded a MRes and a $\mathrm{PhD}$ in Sustainable Energy Systems sponsored by E.ON at Cranfield University. In 2013 he took up the role of Research Fellow at Cranfield University working on both government and industry funded projects focussed on the sustainability in the aerospace and manufacturing sector. His research interests include: multi-criteria analysis of manufacturing and energy systems, modelling of manufacturing and energy systems and 
processes, energy efficiency and life cycle appraisal of manufacturing systems and processes. He has authored more than 15 peer-reviewed, international publications.

Michail Papanikolaou is a Postdoctoral Research Fellow at the Sustainable Manufacturing Systems Centre (SMSC) at Cranfield University, UK. He holds a BEng and MEng in Mechanical Engineering. In 2017, he completed his PhD in Computational Physics at Cranfield University. He currently works on developing numerical modelling techniques towards energy efficient casting processes in the context of the "Small is Beautiful, Phase 2" EPSRC project. His research interests include: Molecular Dynamics simulations, Numerical Optimisation, Finite Element Analysis, Artificial Intelligence, Computational Fluid Dynamics and modelling of Manufacturing Process.

Konstantinos Salonitis is Reader in Manufacturing Systems and the Director of the Manufacturing Systems and Management Masters programme at Cranfield University, UK. He was awarded a PhD in Manufacturing Processes in 2006 from University of Patras. In 2014 he completed a Master in Business Administration from the Hellenic Open University. Konstantinos has participated in more than 10 European Commission funded projects as Project Manager or Technical Site Manager. He joined Cranfield University in February 2012 as a Lecturer and he has published more than 160 research papers in major international journals and internationally referred conferences, authoring also two books and winning funding at international level. His research interests include: simulation and modelling of manufacturing processes, energy efficiency of manufacturing processes and systems, environmental impact assessment of manufacturing processes, abrasive machining processes and rapid manufacturing.

Mark Jolly is Acting Director of Manufacturing, Head of the Sustainable Manufacturing Systems Centre and Professor of Sustainable Manufacturing at Cranfield University, UK. $\mathrm{He}$ received his $\mathrm{PhD}$ in Metallurgy at Cambridge University and worked for more than ten years in the industry at international level. In 1995, Mark moved to the University of Birmingham setting up and managing the Castings Centre and in 1999, he created the Process Modelling Group. Since then he has been PI for 10 UK EPSRC funded grants and CI on 3, winning also other government funding as well as industrial partnerships. Mark was awarded a number of international accolades and prizes. From 2012 Mark heads up the Sustainable Manufacturing Systems Centre at Cranfield University holding also the title of Honorary Professor in the School of Mechanical Engineering at the University of Birmingham. His research interests include: resource efficient manufacturing, process modelling and novel casting processes.

\section{Introduction}

Traditionally, decision making in manufacturing systems is grounded on four main decision-making criteria, namely: (a) cost, (b) time, (c) quality and (d) flexibility (Chryssolouris, 2013). However, the growing concern over the need to adapt modern lives in a way that will not deteriorate the living standards of the future generations by effectively reducing the consumption of resources (e.g. energy and material), has led to the integration of sustainability (Elkington, 2001; World Commission on Environment and Development, 1987) into the aforementioned decision making scheme. According to (Elkington, 1998) sustainable development is founded on three interconnected goals, namely (a) economic prosperity, (b) environmental sustainability and (c) societal well-being, which are widely known as the Triple Bottom Line (TBL). Modern evaluation methodologies such as the Product Sustainability Index (ProdSI) and Process Sustainability Index (ProcSI) incorporate the TBL along with the total product life cycle, and the 6R (Reduce, Reuse, Recycle, Recover, Redesign, and Remanufacture) approach in order to construct a 
comprehensive and metrics-based approach to measure and assess the product/process sustainability performance (Badurdeen et al., 2013; Shuaib et al., 2014).

Decisions in manufacturing systems are driven by metrics, both qualitative and quantitative, which fall into one or more of the previously described decision making criteria. Thus, Multi-Criteria Decision Making (MCDM) models have been developed since the early 1960s, spurred by the complex nature of the decision making process. The purpose of MCDM models is to assist decision makers to select the optimal solution from a set of alternatives based on a number of criteria and their corresponding weights. A typical MCDM model comprises the following steps (Bhushan and Rai, 2007):

1. Definition of the problem

2. Definition of the requirements

3. Establishing the goal

4. Identification of alternatives

5. Development of the evaluation criteria

6. Selection of the decision making tool

7. Application of the tool

8. Evaluation of the solution

MCDM techniques have been widely applied across a variety of fields including natural resource management (Zardari et al., 2015), infrastructure management (Kabir et al., 2014) and financial decision making (Tseng et al., 2018).

Manufacturing systems is one of the most prominent fields for the application of MCDM models because the need for sustainable businesses as well as environmentally friendly manufacturing processes has nowadays become significant. One of the most complex and strategic problems that has been investigated by means of MCDM is the selection of the optimal Flexible Manufacturing Systems (FMS) design. Stam and Kuula (1991) employed the weighted sum method to develop a user friendly Decision Support System (DSS) assisting decision makers to select the optimal FMS configuration. Their model was based on a number of qualitative and quantitative criteria, namely: (a) investment costs, (b) capacity, (c) flexibility, (d) utilisation rate, (e) unit costs and (f) economic risks. A more complex and thorough investigation on the selection of the optimal DMS design was carried out by Chan et al. (2000). They developed a computational framework combining simulation software for the design of FMSs and Artificial Intelligence (AI) algorithms via the ActiveX software framework; an integrated semi-automatic user interface was developed as well. More specifically, an initial set of alternatives was generated by a number of neural networks which were subsequently compared in pairs based on the weights assigned to the criteria. Subsequently, the weighted sum was also calculated and the final ranking of each alternative was evaluated via the Analytic Hierarchy Process (AHP) technique. Liu et al. (2014) developed a MCDM method to assist decision makers with the challenging task of selecting appropriate robots for various industrial applications. The proposed methodology was based on the Interval 2-Tuple Linguistic Technique for Order Preference by Similarity to Ideal Solution (ITL-TOPSIS). A fuzzy TOPSIS MCDM framework was proposed by Vincent and Hu (2010) for the performance evaluation of multiple manufacturing plants. In this study, five manufacturing plants were assessed with respect to their (a) productivity, (b) production capacity, (c) cost, (d) inventory amount and (e) quality cost while the yielded results were verified against each company's audit data. 
Despite the wide application of MCDM models in manufacturing systems, their application on metal casting processes is still an under-investigated topic. The development of a decision-making framework for casting processes is of significant importance as casting is one of the most energy intensive manufacturing processes; mostly due to the high energy demands during the melting and holding processes (Pagone et al., 2019). The study here presented spotlights the High Pressure Die Casting (HPDC) process which is a permanent mould, metal casting process suitable for high production volumes (Jolly, 2003). Until the late Nineties of the last century, HPDC had been considered a low cost and technology manufacturing process while research investigations around HPDC were mainly directed towards the equipment rather the process itself (Casarotto et al., 2012). Although the last two decades of sheer growth of the global automotive industry along with the systematic research in material science (Casarotto et al., 2012) have promoted significant improvements in the HPDC technology, both "traditional" HPDC processes and materials are still a popular option to produce large volumes of relatively simple castings. Moreover, another research direction, which can enhance the competitiveness of the HPDC process and has not yet been thoroughly investigated, is its process sustainability.

In this study, three alternative materials along with their corresponding HPDC processes suitable to produce passenger vehicle parts, will be assessed over several phases of their product life cycle using a deterministic MCDM tool that includes, besides the traditional performance metrics (cost, quality and time), environmental sustainability Key Performance Indicators (KPIs). All the metrics under examination are normalised by the mass of the component to make the results of the current analysis applicable to various automotive parts manufactured using the HPDC process and characterised by comparable mechanical properties.

\section{Product and process performance indicators}

Several metrics describing the specifications of the metal alloys during the life phases of the product have been considered in this study. Their positive or negative impact has been assessed considering the effect of an increase for each quantity. Furthermore, the employed metrics have been classified under four categories, namely: (a) cost, (b) time, (c) quality and (d) sustainability (Table 1). More specifically, based on the TBL approach, the sustainability metrics considered fall under the environmental sustainability component.

\subsection{Cost}

Considerable research efforts have been devoted to cost estimation in manufacturing although a large part of them focused on products at their design stage. It is possible to identify several alternative approaches (NASA, 2015) based on:

- Experience and similarity to existing products (Duverlie and Castelain, 1999)

- Process mapping with relevant empirical equations (Feng et al., 1996; Ou-Yang and Lin, 1997)

- Geometric features of the product (Farineau et al., 2001) that can be parameterised using existing data (Cavalieri et al., 2004; Fagade and Kazmer, 2000)

On the contrary, studies on specific manufacturing processes are less common (Chougule and Ravi, 2006). (Bidanda et al., 1998) developed a cost estimation framework especially for gravity die casting processes to be also used by people with limited technical knowledge. Chougule and Ravi (2006) presented a cost estimation method based on the product weight and the overall material efficiency of the plant. Their method is particularly suitable for foundries that produce large volumes of similar products, such as HPDC foundries. Moreover, the authors suggested that the total cost of a casting can be decomposed into five main categories, namely: material, tooling, labour, energy and overheads. 
In the current investigation, labour and overhead costs are assumed to be comparable and will be ignored, considering that the casting process for the three alloys under investigation is the same (HPDC). Thus, the absolute value of the overall specific cost $c_{o}$ is not an estimate of the actual overall cost referring to the unit mass of final product but only an approximate assessment of the main differences in cost between the alternatives.

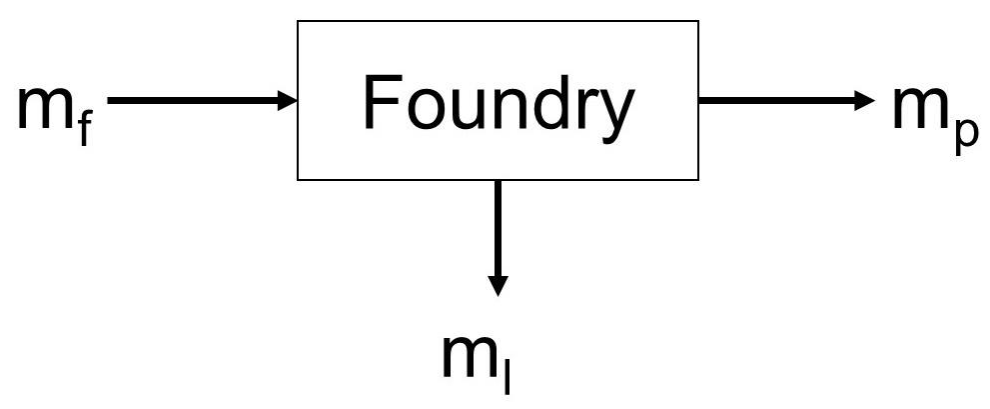

Figure 1: Foundry key mass flows considered in this study

Futhermore, in this work cost and specific cost per unit mass will be distinguished using, respectively, the capital $C$ and lowercase letter $c$. The energy and material costs are specified by the subscript $E$ and $M$. Focusing on the material costs first, the metric to be used in the MCDM study is the normalised cost by mass of final product $c_{M}$ but the data available (Granta Design Limited, 2017) is normalised by mass of foundry feedstock $m_{f}$, i.e. $c_{M, f}$. To calculate $c_{M}$ from $c_{M, f}$ it is observed that, as illustrated in Figure $1, m_{f}$ is equal to the sum of the final product mass $m_{p}$ and the mass that leaves the foundry with no added value $m_{l}$ (e.g. dross, scrap not internally recycled, swarf etc.). Moreover, the material $\operatorname{cost} C_{M}$ can be obtained multiplying the normalised material $\operatorname{cost} c_{M}$ by mass:

$$
C_{M, i}=c_{M, i} m_{i}
$$

where the subscript $i$ may refer to product $(p)$, feedstock $(f)$ or loss $(l)$ mass. After some algebraic manipulation and with the help of Eq. (1) the sought expression that links $c_{M}$ to $c_{M, f}$ reads:

$$
c_{M}=\frac{c_{M, f}}{1-f_{M, l}}
$$

where $f_{M, l}$ is the fraction of the loss mass over the feedstock mass $\left(f_{M, l}=m_{l} / m_{f}\right)$.

Additionally, the specific cost of energy normalised by the mass of final product $c_{E}$ can be calculated using the specific cost of electricity $c_{E, e l}$ and natural gas $c_{E, g}$ per energy unit. The specific costs of the two energy sources, multiplied by the corresponding contribution fractions to the total energy consumption $\left(f_{E, e l}\right.$ and $\left.f_{E, g}\right)$ are added, considering that there are no additional energy sources used in the foundry. This sum is subsequently multiplied by the overall specific energy consumption of the manufacturing process $e_{m}$ and $c_{E}$ is estimated according to:

$$
c_{E}=e_{m}\left(f_{E, e l} c_{E, e l}+f_{E, g} c_{E, g}\right)
$$

Finally, the overall specific cost is obtained by adding up the material and energy contributions: $c_{o}=$ $c_{M, p}+c_{E}$. 
Another aspect that may have an impact on the profitability of a HPDC foundry is the life of the dies which are made of special steel and often characterised by complex geometries. The life of the dies is affected by the material being cast (Black et al., 2013) and frequent substitutions may lead to increased cost. The order of magnitude of cycles that a die can withstand before being substituted $n_{d}$ is included in the present analysis.

\subsection{Quality}

Within the class of quality, two main sub-classes have been selected to be included in the present analysis: castability and mechanical properties.

\subsubsection{Castability}

Four quantities have been considered to describe the castability of the alternative metal alloys as a measure of the expected manufacturing quality: (a) volumetric solidification shrinkage $V_{S S}$, (b) linear thermal contraction of the solid phase $\alpha_{s}$, (c) freezing temperature range $\Delta T_{f}$ and (d) solidus temperature $T_{s}$.

The volumetric solidification shrinkage has been estimated based on the metal elements that comprise each alloy according to the Kopp-Neumann rule (Quested et al., 2000; Valencia and Yu, 2002):

$$
V_{s S}=\sum_{i=1}^{n} V_{s s, i} x_{i}
$$

where $n$ is the number of the alloy elements and $x$ the corresponding molar fraction.

Three shrinkage regimes are generally identified in metal casting processes. These are here listed in chronological order: liquid contraction, solidification shrinkage and solid contraction (Black et al., 2013). In HPDC the first two regimes are more strictly related to internal defects, whereas solid contraction mainly affects dimensional tolerances, draft angles and allowances (North American Die Casting Association, 2018). Liquid contraction is considered the least harmful of the three because most of it happens before filling the die (North American Die Casting Association, 2018). For this particular reason, it has been ignored in this analysis. Since the effects of solidification and solid-phase shrinkage on the casting quality are quite different, a separate criterion for each of them has been considered. The choice to assess separately the two types of contraction allows to consider different ways to measure shrinkage (i.e. volumetric solidification versus linear solid-phase contraction) without affecting the validity of the comparison (see Section3).

Furthermore, castability is significantly affected by fluidity (Black et al., 2013). With regard to metal casting, it has been well-established that larger freezing ranges are usually associated with reduced fluidity and, thus, increased defects (Bastien et al., 1962). However, specific studies on the HPDC process (with Al-Si alloys) showed that in this specific case the solidus temperature dominates controlling fluidity over the freezing range. More specifically, the lower the solidus temperature, the higher the fluidity (Han and $\mathrm{Xu}, 2005)$. Moreover, large freezing ranges are undesirable in HPDC because they prevent rapid ejection of the casting from the mould increasing exposure to residual stresses (or, in the worst case scenario, hot tearing), while heat treatment is generally unsuitable for HPDC products (Black et al., 2013). 
Table 1: Categorised selected metrics of the metal alloys to produce a passenger car part with a high pressure die casting process.

\begin{tabular}{|c|c|c|c|}
\hline Quantity & Impact & Category & Product life phase \\
\hline Overall specific cost $c_{o}$ & negative & cost & LCA cradle to gate \\
\hline Volumetric solidification shrinkage $V_{S S}$ & negative & quality & manufacturing process \\
\hline Solid linear thermal contraction $\alpha_{s}$ & negative & quality & manufacturing process \\
\hline Freezing temperature range $\Delta T_{f}$ & negative & quality & manufacturing process \\
\hline Solidus temperature $T_{s}$ & negative & quality & manufacturing process \\
\hline Tensile strength $F_{t u}$ & positive & quality & use phase, design specification \\
\hline Modulus of elasticity $E_{t}$ & positive & quality & use phase, design specification \\
\hline Yield strength $F_{y}$ & positive & quality & use phase, design specification \\
\hline Elongation to break $\varepsilon_{b}$ & positive & quality & use phase, design specification \\
\hline Fracture toughness $k_{I c}$ & positive & quality & use phase, design specification \\
\hline Corrosion depth in atmosphere $d_{c a}$ & negative & $\begin{array}{l}\text { environmental sustainability and } \\
\text { quality }\end{array}$ & use phase \\
\hline Density $\rho$ & negative & $\begin{array}{l}\text { environmental sustainability and } \\
\text { quality }\end{array}$ & use phase, design specification \\
\hline Overall specific energy consumption $e_{o}$ & negative & environmental sustainability & LCA cradle to gate \\
\hline Overall carbon intensity $C I_{o}$ & negative & environmental sustainability & LCA cradle to gate \\
\hline Primary production specific water consumption $v_{w p}$ & negative & environmental sustainability & raw material extraction and processing \\
\hline Manufacturing energy efficiency $\eta_{o m}$ & positive & environmental sustainability & manufacturing process \\
\hline Manufacturing Operational Material Efficiency $O M E_{m}$ & positive & environmental sustainability & manufacturing process \\
\hline Die life in number of cycles $n_{d}$ & positive & $\begin{array}{l}\text { cost and environmental } \\
\text { sustainability }\end{array}$ & manufacturing process \\
\hline Heat of fusion $\Delta H_{f}$ (proportional to machine cycle time) & negative & time & manufacturing process \\
\hline
\end{tabular}




\subsubsection{Mechanical properties}

HPDC products are known to be significantly affected by micro-porosity (Jolly, 2003) which reduces ductility and toughness alongside other mechanical properties (Black et al., 2013). Moreover, typical problems that can potentially be encountered in material substitution are reduced corrosion resistance and rigidity for thinner cross section designs (Black et al., 2013). For the aforementioned reasons, a number of mechanical properties (tensile strength $F_{t u}$, modulus of elasticity $E_{t}$, yield strength $F_{y}$, elongation to break $\varepsilon_{b}$, fracture toughness $k_{I c}$, corrosion depth in atmosphere $d_{c a}$ ) have been considered as additional criteria in this analysis, although the minimum values of these properties for every alloy considered meet the minimal design requirements. These quantities express a measure of quality by rewarding materials with a larger margin above the minimum design requirements. Furthermore, density $\rho$ has a very prominent importance among the design criteria of modern automotive parts because it significantly affects fuel economy and ride quality of the vehicles.

\subsection{Environmental sustainability}

The energy efficiency of a process is one of the most dominant factors affecting environmental sustainability, especially in the case of energy-intensive processes such as metal casting (Pagone et al., 2019). The "cradle to gate" specific energy consumption $e_{o}$ is being considered in the context of this analysis. Specific energy consumption takes into account the contribution during primary production of the material $e_{p}$ as well as the specific energy of the entire manufacturing process $e_{m}$ (occasionally referred to as $S E C$ ) through the Operational Material Efficiency of the full manufacturing process $O M E_{m}$ :

$$
e_{o}=\frac{e_{p}}{O M E_{m}}+e_{m}
$$

The specific carbon dioxide emissions associated with the required energy are assessed using the carbon intensity $C I$, which takes into account both the primary production process and the manufacturing steps. The manufacturing carbon intensity has been calculated considering the fraction of electric energy and natural gas consumed along with the corresponding carbon dioxide specific emissions, similarly to Eq. (3) by substituting the specific cost with the carbon intensity. This assessment does not account for the energy consumed for the transportation of materials and the production of the HPDC machinery that are assumed to be comparable for all the alternatives considered and can thus be ignored in a comparative analysis.

The specific energy consumption of the manufacturing process $e_{m}$ provides an absolute value of the foundry overall energy efficiency. However, it does not take into consideration its performance in comparison to the ideal case for the specific alloy being processed. Thus, a measure of the manufacturing energy efficiency $\eta_{o m}$ has been proposed (Pagone, Papanikolaou, et al., 2018; Pagone, Salonitis, et al., 2018):

$$
\eta_{\text {om }}=\frac{\Delta h_{l}}{e_{m}}
$$

where $\Delta h_{l}$ is the specific enthalpy rise from ambient to the liquidus temperature. Finally, the impact of the primary material production on water consumption $v_{w p}$ has been evaluated in order to consider also a non energy-related environmental sustainability indicator.

\subsection{Time}

Machine cycle time is an important factor affecting the productivity of HPDC foundries (Black et al., 2013). If no plant-specific data is available, this metric can be approximated by the heat of fusion $\Delta H_{f}$ of the material which has been found to be proportional to the machine cycle time (Davis, 1998). However, 
considering that this is an indirect measure, the consequent higher uncertainty can be taken into account by associating a reduced weight to this criterion in the multi-criteria assessment.

\section{Multiple-criteria decision-making methods}

Several methods, capable of considering multiple conflicting criteria, have been developed in the last decades to support decision-making. These models can be classified based on the type of data they support as deterministic, stochastic or fuzzy. Some of the more popular methods are the Weighted Sum Model (WSM), the Weighted Product Model (WPM), the ELimination Et Choix Traduisant la REalité (ELECTRE), the Analytic Hierarchy Process (AHP) and the Technique for Order of Preference by Similarity to Ideal Solution (TOPSIS). Several variations and improvements of the mentioned methods have been proposed over the years. Recently, TOPSIS has seen a significant grow in popularity since it is perceived that it can effectively address some of the shortcomings of the other methods. (Triantaphyllou et al., 1999)

In this investigation a deterministic TOPSIS analysis has been performed. The TOPSIS method is based on the concept that the optimal alternative should have the minimum distance from the ideal solution $\left(A^{+}\right)$and the maximum distance from the negative ideal solution $\left(A^{-}\right)$. For each metric, the best and worst value among the options will be identified. These values, when combined, form the positive and negative ideal solutions. The options are ranked based on similarity $s_{i}^{-}$to $A^{-}$: the higher the value of $s_{i}^{-}$, the better the option. (Ishizaka and Nemery, 2013)

The decision matrix $(X)$ of the TOPSIS method summarises the $n$ decision criteria values for $m$ different alternative options.

$$
X=\left[\begin{array}{cccc}
x_{1,1} & x_{1,2} & \cdots & x_{1, n} \\
x_{2,1} & x_{2,2} & \cdots & x_{2, n} \\
\vdots & \vdots & \ddots & \vdots \\
x_{m, 1} & x_{m, 2} & \cdots & x_{m, n}
\end{array}\right]
$$

The steps of the TOPSIS technique are briefly listed below.

1. Construction of the normalised decision matrix $R$. The elements of this matrix are the ratings $x_{i, j}$ of each alternative solution $A_{i}$ for each criterion $C_{j}$ normalised as follows:

$$
r_{i, j}=\frac{x_{i, j}}{\sqrt{\sum_{i=1}^{m} x_{i, j}^{2}}} \quad \forall i \in[1, n] \quad \text { and } \quad \forall j \in[1, m]
$$

This allows the comparison of ratings between different criteria.

2. Construction of the Weighted Normalised Decision matrix $V$. The elements of $V$ are estimated according to:

$$
v_{i, j}=r_{i, j} w_{j} \quad \forall j \in[1, m]
$$

where $w_{j}$ is the weight corresponding to the Criterion $C_{j}$.

3. Determination of the ideal and negative-ideal solutions as follows: 


$$
A_{j}^{+}=\max _{1 \leq j \leq n}\left(x_{i, j}\right) \text { and } A_{j}^{-}=\min _{1 \leq j \leq n}\left(x_{i, j}\right)
$$

4. Determination of the distances to the ideal and negative ideal solutions respectively:

$$
\begin{aligned}
& d_{i}^{+}=\sqrt{\sum_{j=1}^{n}\left(v_{i, j}-v_{j}^{+}\right)^{2}} \quad \forall i \in[1, m] \\
& d_{i}^{-}=\sqrt{\sum_{j=1}^{n}\left(v_{i, j}-v_{j}^{-}\right)^{2}} \quad \forall i \in[1, m]
\end{aligned}
$$

5. Estimation of the closeness to the ideal solution according to:

$$
s_{i}=\frac{d_{i}^{-}}{d_{i}^{+}+d_{i}^{-}} \quad \forall i \in[1, m]
$$

It is evident that $s_{i}=1$ when $A_{i}=A^{+}$and $s_{i}=0$ when $A_{i}=A^{-}$.

6. Ranking of the alternative solutions by the descending value of $s_{i}$

\section{Results and discussion}

The alternative materials considered in this study for the production of a passenger car component are three typical alloys used in HPDC processes, all suitable for automotive parts. These are: (a) aluminium A380, (b) magnesium AZ91D and (c) zinc ZA-8. The first two alloys are cast in a cold chamber machine whereas the last one in a hot chamber. The specifications of the facility processing aluminium alloys have been provided by an industrial contact and are based on data collected monthly for two years. The information about the magnesium and zinc alloy facilities has been collected from the open literature and is provided on a monthly basis for at least one year. The main reference for these two foundries is a report of the USA Department of Energy (Eppich, 2004). The values and weights for each criterion selected are presented in Table 2 where values without any reference have been calculated as described in Section 2 or are confidential. Weights have been distributed in equal proportion to each category (i.e. cost, quality, environmental sustainability, time) and to the individual metrics (within each category), as reported in Table 1. It is important to note that some metrics belong to two categories (e.g. material density) and, thus, their weight reflects this peculiarity. Finally, as reported in Section 2.4, since the material heat of fusion is an indirect measure of cycle time, its weight has been reduced to limit the impact of this metric on the final outcome of the analysis. The additional calculations required before executing the TOPSIS analysis are described in the following paragraphs.

To evaluate the overall value of the overall specific $\operatorname{cost} c_{o}$, the specific cost of each alloy normalised by the mass of the foundry feedstock $c_{M, f}$ has been taken from the database Edupack (Granta Design Limited, 2017). The fraction of the feedstock mass that leaves the foundry with no added value $f_{M, l}$ (Eq. (2)) has been assumed to be equal to $10 \%$ for all the materials under examination. Unfortunately, no specific information in this regard is available, except from data on melt dross of about $7 \%$ for the zinc alloy facility (Eppich, 2004). The choice to increase this value to $10 \%$ is motivated by the observation that a few other process steps will generate material losses in the foundry with no added value. On the other hand, this 
percentage has not been increased further because no additional value has been associated to the unrecoverable metal in the calculations. Furthermore, according to (Eppich, 2004) a percentage between $10 \%$ and $30 \%$ of the feedstock mass value may be recovered. It is expected that the combination of these two opposite effects will reduce the relevant error within the level of approximation of the entire analysis.

For the calculation of the volumetric solidification shrinkage $V_{S s}$, the individual values for each metal alloy have been taken from (Campbell, 2003) and the composition of the alloys from the online database ("Online Materials Information Resource - MatWeb", n.d.).

The two components of the overall specific energy consumption $e_{o}$, i.e. primary production $e_{p}$ and manufacturing $e_{m}$ have been estimated using the database Edupack (Granta Design Limited, 2017) and the report by (Eppich, 2004) with direct foundry measurements (aluminium alloy processing plant) respectively. These energy values have been used also to calculate $c_{o}$ and $C I_{o}$ as described in Section 2 .

Carbon intensities for the primary production have been taken from the database Edupack (Granta Design Limited, 2017). For the calculation of the corresponding values during the manufacturing steps, the carbon intensity associated to electric and natural gas energy has been considered to be equal to $76.64 \mathrm{~g}_{\mathrm{CO}_{2}} / \mathrm{MJ}$ (European Environment Agency, 2018) and $56.1 \mathrm{~g}_{\mathrm{CO}_{2}} / \mathrm{MJ}$ (German Environment Agency, 2016) respectively.

The manufacturing energy efficiency $\eta_{o m}$ has been taken from a previous publication of the authors (Pagone, Papanikolaou, et al., 2018).

(a)

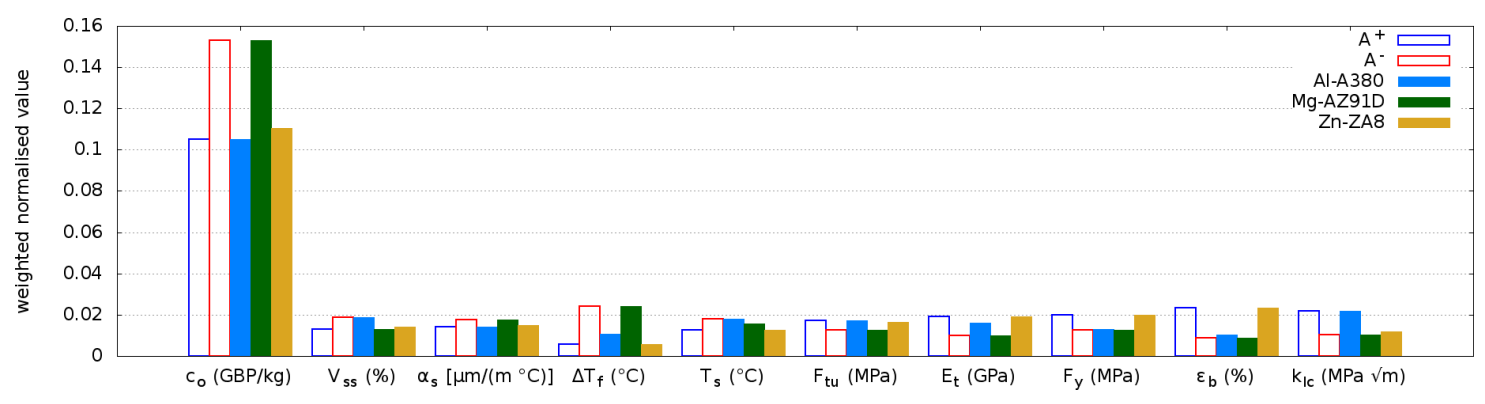

(b)

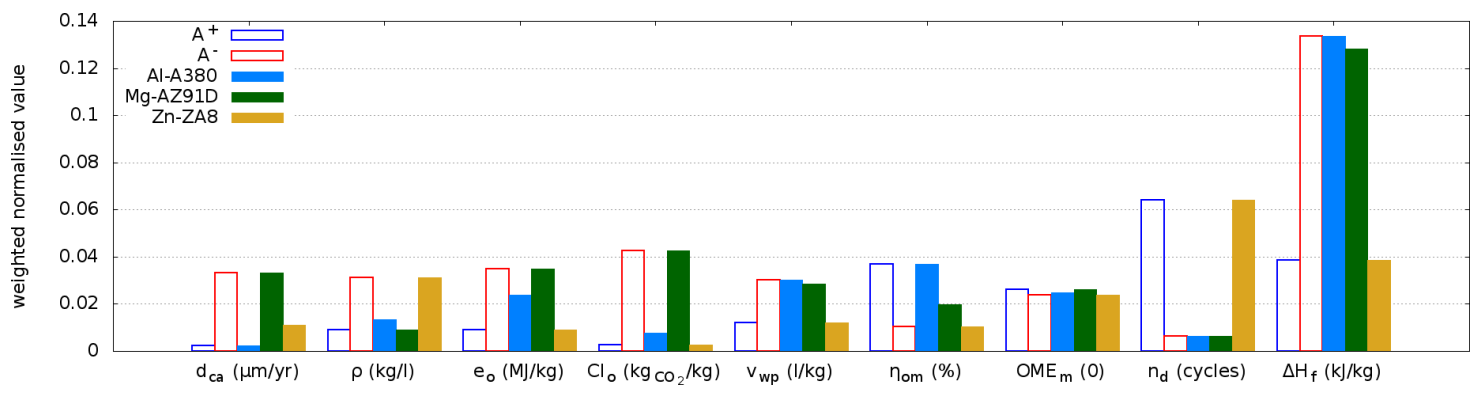

Figure 2: Weighted normalised values of the criteria in: (a) the cost and quality domains to compare different metal alloys to produce a unit mass of a passenger car component with a high pressure die casting process, $(b)$ the environmental sustainability and time domains to compare different metal alloys to produce a unit mass of a passenger car component with a high pressure die casting process. The values of the positive $A^{+}$and negative $A^{-}$ideal solutions are shown. 
Table 2: Values and weights of criteria considered to compare different metal alloys to produce a passenger car part with a high pressure die casting process. A reference to the source is provided next to the values that have been not calculated or are confidential.

\begin{tabular}{|c|c|c|c|c|c|}
\hline Quantity & Units & Weight & Al-A380 & Mg-AZ91D & Zn-ZA8 \\
\hline Overall specific cost $c_{o}$ & $\mathrm{GBP} / \mathrm{kg}$ & 0.8 & 2.09 & 3.04 & 2.19 \\
\hline Volumetric solidification shrinkage $V_{s s}$ & $\%$ & 0.1 & 6.23 & 4.36 & 4.65 \\
\hline $\begin{array}{l}\text { Solid linear thermal contraction } \alpha_{s} \text { ("MakeItFrom.com: } \\
\text { Material Properties Database", n.d.) }\end{array}$ & $/(\mathrm{m})$ & 0.1 & 22 & 27 & 23 \\
\hline $\begin{array}{l}\text { Freezing temperature range } \Delta T_{f} \text { ("'Online Materials } \\
\text { Information Resource - MatWeb", n.d.) }\end{array}$ & & 0.1 & 55 & 125 & 29 \\
\hline $\begin{array}{l}\text { Solidus temperature } T_{s} \text { (“'Online Materials Information } \\
\text { Resource - MatWeb”, n.d.) }\end{array}$ & & 0.1 & 538 & 470 & 375 \\
\hline Tensile strength $F_{t u}($ Granta Design Limited, 2017) & $\mathrm{MPa}$ & 0.1 & 340 & 245.5 & 322.5 \\
\hline Modulus of elasticity $E_{t}$ (Granta Design Limited, 2017) & $\mathrm{GPa}$ & 0.1 & 71 & 45 & 86 \\
\hline Yield strength $F_{y}$ (Granta Design Limited, 2017)] & $\mathrm{MPa}$ & 0.1 & 160 & 155 & 245 \\
\hline $\begin{array}{l}\text { Elongation to break } \varepsilon_{b} \text { (“Online Materials Information } \\
\text { Resource - MatWeb", n.d.) }\end{array}$ & $\%$ & 0.1 & 3.5 & 3 & 8 \\
\hline Fracture toughness $k_{I C}($ Granta Design Limited, 2017) & $\operatorname{MPa} \sqrt{\mathrm{m}}$ & 0.1 & 27.05 & 13 & 15 \\
\hline Corrosion depth in atmopshere $d_{c a}$ (Davis, 1998) & /yr & 0.13 & 1.39 & 19.57 & 6.57 \\
\hline Density $\rho$ (Granta Design Limited, 2017) & $\mathrm{kg} /$ & 0.13 & 2.74 & 1.81 & 6.3 \\
\hline Overall specific energy consumption $e_{o}$ & $\mathrm{MJ} / \mathrm{kg}$ & 0.16 & 349.35 & 486.87 & 130.82 \\
\hline Overall carbon intensity $C I_{o}$ & $\mathrm{~kg}_{\mathrm{CO}_{2}} / \mathrm{kg}$ & 0.16 & 12.57 & 69.84 & 4.32 \\
\hline $\begin{array}{l}\text { Primary production specific water consumption } v_{w p} \text { (Granta } \\
\text { Design Limited, 2017) }\end{array}$ & $/ \mathrm{kg}$ & 0.16 & 1055 & 998 & 417 \\
\hline Manufacturing energy efficiency $\eta_{o m}$ & $\%$ & 0.16 & 6.137 & 3.284 & 1.715 \\
\hline Manufacturing Operational Material Efficiency $O M E_{m}$ & l & 0.16 & 0.545 & 0.57 (Eppich, 2004) & 0.52 (Eppich, 2004) \\
\hline $\begin{array}{l}\text { Die life in number of cycles } n_{d} \text { (Schrader and Elshennawy, } \\
\text { 2000) }\end{array}$ & cycles & 0.24 & $10^{5}$ & $10^{5}$ & $10^{6}$ \\
\hline $\begin{array}{l}\text { Heat of fusion } \Delta H_{f} \text { ("Online Materials Information Resource } \\
\text { - MatWeb", n.d.) (proportional to machine cycle time) }\end{array}$ & $\mathrm{kJ} / \mathrm{kg}$ & 0.7 & 389 & 373 & 112 \\
\hline
\end{tabular}


As far as the overall specific cost criterion is considered (Figure 2a), the aluminium alloy performs best, closely followed by the zinc-based ZA-8 alloy, with magnesium AZ91D being significantly less competitive. However, it can be observed that the number of cycles until the end of life of the die $n_{d}$ is much higher for the Zn-ZA8 alloy (Figure 2b).

On the other hand, with respect to the quality criteria, Zn-ZA8 appears to have superior properties compared to Mg-AZ91D and Al-A380. This is because in most of the quality criteria examined, Zn-ZA8 is ranked among the top 2 performing materials. More specifically, the Zn-ZA8 alloy has a lower freezing temperature range $\Delta T_{f}$, lower solidus temperature $T_{s}$, higher modulus of elasticity $E_{t}$, yield strength $F_{y}$ and about twice the elongation break $\varepsilon_{b}$ compared to the other two materials. The Al-A380 alloy performs better just as far as the (a) solid linear thermal contraction $\alpha_{s}$, (b) tensile strength $F_{t u}$ and (c) fracture toughness $k_{I c}$ criteria are considered. However, with respect to the aforementioned criteria there is not much difference between the top performing alloy (Al-A380) and the succeeding one, which in most cases is the Zn-ZA8 alloy. Mg-AZ91D performs better than the other 2 alloys with respect to just 1 quality criterion, the corrosion depth in atmosphere $d_{c a}$.

With regard to the sustainability criteria, the only case where magnesium AZ91D appears to be a winner, with zinc ZA- 8 being by far the least desirable option, is the criterion of density $\rho$. This observation partially justifies the efforts of the automotive industry in the past years to increment the adoption of this material to increase the fuel efficiency of vehicles. However, by observing many other environmental sustainability indicators, such as the primary production specific water consumption $v_{w p}$, overall carbon intensity $C I_{o}$, the overall specific energy consumption $e_{o}$ and manufacturing operational material efficiency $O M E_{m}$, it appears that the zinc ZA-8 alloy is the most favourable option. Consequently, the argument that substituting conventional materials with lighter ones lacks critical information and needs to be re-evaluated. The results presented in Figure 2b indicate that Zinc-based alloy ZA-8 is clearly the best performer, often by a large extent. It is interesting to note that the only exception to this observation is the manufacturing energy efficiency of the plant $\eta_{o m}$ where ZA-8 is the worst option, showing that there is an opportunity to further improve the performance of ZA-8 foundries, pushing them to approach their theoretical minimum energy consumption. This hypothesis has been verified in a previous study which suggests that the melting process of ZA-8, in particular, can be improved with a great potential benefit for the overall foundry energy performance (Pagone, Papanikolaou, et al., 2018).

In most of the casting processes, such as sand casting, the solidification time is not as important as in HPDC. This is because HPDC is one of the most repetitive and high-production-rate casting processes; consequently, the solidification time significantly affects the overall process efficiency. As to the time criterion, the Zn-ZA8 alloy has the lowest heat of fusion $\Delta H_{f}$, which is proportional to the machine cycle time. The values of $\Delta H_{f}$ for the Al-A380 and Mg-AZ91D alloys are comparable between them and more than twice as high compared to Zn-ZA8.

In Figure 3 the criteria are combined to provide a simple score for each one of the 3 alloys under investigation (i.e. sum of the distances $S^{-}$of the alternative to the negative ideal solution $A^{-}$) and presented in a single bar chart. It is obvious that the zinc alloy ZA-8 is, by a large extent, the best choice with aluminium A380 ranked as the second best alternative and magnesium AZ91D coming last by a long margin. 


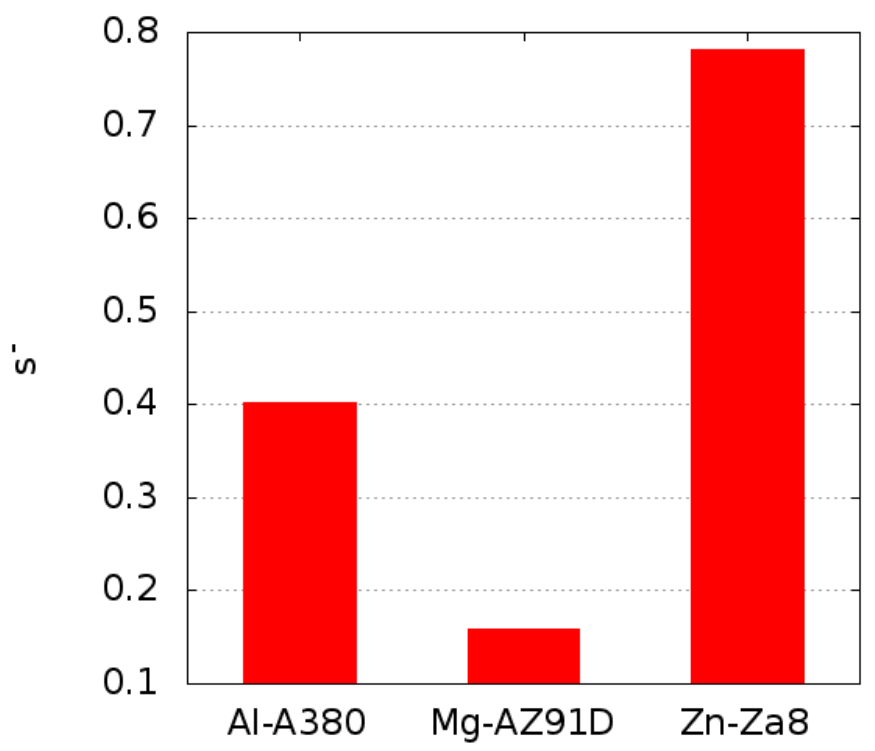

Figure 3: Similarity index $s^{-}$to the negative ideal solution of different metal alloys to produce a unit mass of a passenger car component with a high pressure die casting process. The best alternative has the highest score.

\section{Conclusions}

Typically, decision making in manufacturing systems is based on five main decision making criteria, namely: (a) cost, (b) time, (c) quality, (d) flexibility and (e) environmental sustainability. In the context of a manufacturing system, each one of the aforementioned decision making criteria is quantified by a large number of metrics, both qualitative and quantitative. As a result, decision making in such systems is not a trivial problem and Multi-Criteria Decision-Making (MCDM) methods are being implemented to assist managers and production engineers.

The objective of this investigation is the selection of the most suitable alloy for a High Pressure Die Casting (HPDC) foundry producing automotive components. For the purposes of this study four criteria have been considered, namely (a) cost, (b) quality, (c) environmental sustainability (which traditionally is not much considered) and (d) productivity (time), to assess the performance of each material. The deterministic Technique for Order Preference by Similarity to Ideal Solution (TOPSIS) method has been adopted to weigh and combine the different criteria and drive decision making. Each one of the four classes of criteria examined was assessed using a number of metrics normalised by mass to generalise the yielded results. For example, the performance of each material with regards to cost was assessed using the overall specific cost $\left(c_{o}\right)$ and die life in number of cycle $\left(n_{d}\right)$ metrics. The ratings of each alternative with respect to each metric considered were later compared to the ideal and negative ideal solutions in order to identify the most suitable material for the particular application.

The results indicate that the Al-A380 alloy has the lowest overall specific cost, closely followed by the ZnZA8 alloy. However, this saving related to the Al-A380 alloy is partially offset by the much higher expected life of the Zn-ZA8 alloy dies. In general, the Zn-ZA8 alloy is characterised by superior performance when compared to the other two materials with respect to quality. However, the Al-A380 alloy has a slightly lower solid thermal contraction coefficient, a marginally higher tensile strength and significantly higher fracture toughness than the Zn-ZA8 alloy. The only quality metric that ranks the Mg-AZ91D alloy in the 
first position is corrosion resistance in atmosphere. Similarly, all of the environmental sustainability metrics taken into consideration, with the exception of manufacturing energy efficiency, suggest that Zn-ZA8 is the most favourable material. The low performance of Zn-ZA8 in terms of manufacturing energy efficiency was attributed to the energy-wise ineffective melting process of the zinc foundry considered. Zn-ZA8 was also proven to be the most efficient alloy with respect to productivity due to its comparatively low heat of fusion which allows for faster solidification process and consequently lower cycle time.

The results obtained were based on the general assumption that each category of metrics is equally important for the decision maker and that the same is true for the metrics within each category (with the only, minor exception of a reduced weight for the material heat of fusion representing productivity). However, the following areas can be explored in further studies to assess the sensitivity of the obtained ranking:

- consider different weight distributions with unbalanced preferences between categories and specific metrics;

- consider the uncertainty of the input data using stochastic or fuzzy distributions;

- use other compensatory MCDM algorithms;

- include the use and end-of-life phase of the automotive product considered;

- add more metrics, especially within the time and social sustainability categories.

\section{Acknowledgements}

This work has been funded by the UK EPSRC "Energy Resilient Manufacturing 2: Small is Beautiful Phase 2 (SIB2)" (EP/P012272/1). The authors would like to thank Dr Konstantinos Georgarakis for his thoughtprovoking considerations during the development of the case study.

\section{References}

Badurdeen, F., Shuaib, M.A., Lu, T. and Jawahir, I.S. (2013), "Sustainable Value Creation in Manufacturing at Product and Process Levels: A Metrics-Based Evaluation", Handbook of Manufacturing Engineering and Technology, Springer, pp. 1-28.

Bastien, P., Armbruster, J.C. and Azov, P. (1962), "Flowability and viscosity", AFS Transactions, Vol. 70, pp. 400-409.

Bhushan, N. and Rai, K. (2007), Strategic Decision Making: Applying the Analytic Hierarchy Process, Springer Science \& Business Media.

Bidanda, B., Kadidal, M. and Billo, R.E. (1998), "Development of an intelligent castability and cost estimation system”, International Journal of Production Research, Taylor \& Francis Group, Vol. 36 No. 2, pp. 547-568.

Black, J.T., Kohser, R.A. and DeGarmo, E.P. (2013), DeGarmo's Materials and Processes in Manufacturing., John Wiley \& Sons.

Campbell, J. (2003), Castings, Elsevier.

Casarotto, F., Franke, A.J. and Franke, R. (2012), "High-pressure die-cast (HPDC) aluminium alloys for automotive applications", Advanced Materials in Automotive Engineering, Elsevier, pp. 109-149. 
Cavalieri, S., Maccarrone, P. and Pinto, R. (2004), "Parametric vs. neural network models for the estimation of production costs: A case study in the automotive industry", International Journal of Production Economics, Elsevier, Vol. 91 No. 2, pp. 165-177.

Chan, F.T.S., Jiang, B. and Tang, N.K.H. (2000), "The development of intelligent decision support tools to aid the design of flexible manufacturing systems", International Journal of Production Economics, Elsevier, Vol. 65 No. 1, pp. 73-84.

Chougule, R.G. and Ravi, B. (2006), "Casting cost estimation in an integrated product and process design environment", International Journal of Computer Integrated Manufacturing, Taylor \& Francis, Vol. 19 No. 7, pp. 676-688.

Chryssolouris, G. (2013), Manufacturing Systems: Theory and Practice, Springer Science \& Business Media, New York.

Davis, J.R. (1998), Metals Handbook: Desk Edition, 2nd ed., ASM International.

Duverlie, P. and Castelain, J.M. (1999), "Cost Estimation During Design Step: Parametric Method versus Case Based Reasoning Method", The International Journal of Advanced Manufacturing Technology, Springer-Verlag London Limited, Vol. 15 No. 12, pp. 895-906.

Elkington, J. (1998), Cannibals with Forks : The Triple Bottom Line of 21st Century Business, New Society Publishers.

Elkington, J. (2001), "The triple bottom line for 21st century business", The Earthscan Reader in Business and Sustainable Development, Earthscan, London, pp. 20-43.

Eppich, R.E. (2004), Energy Use in Selected Metal Casting Facilities -2003, United States.

European Environment Agency. (2018), Overview of Electricity Production and Use in Europe, available at: https://www.eea.europa.eu/data-and-maps/indicators/overview-of-the-electricity-production2/assessment-4.

Fagade, A.A. and Kazmer, D.O. (2000), "Early cost estimation for injection molded components", Journal of Injection Molding Technology, Vol. 4 No. 3, pp. 97-106.

Farineau, T., Rabenasolo, B., Castelain, J.M., Meyer, Y. and Duverlie, P. (2001), "Use of Parametric Models in an Economic Evaluation Step During the Design Phase", The International Journal of Advanced Manufacturing Technology, Springer-Verlag London Limited, Vol. 17 No. 2, pp. 79-86.

Feng, C.-X. (Jack), Kusiak, A. and Huang, C.-C. (1996), "Cost evaluation in design with form features", Computer-Aided Design, Elsevier, Vol. 28 No. 11, pp. 879-885.

German Environment Agency. (2016), CO2 Emission Factors for Fossil Fuels, available at: https://www.umweltbundesamt.de/en/publikationen/co2-emission-factors-for-fossil-fuels.

Granta Design Limited. (2017), “CES Edupack”, Cambridge.

Han, Q. and Xu, H. (2005), "Fluidity of alloys under high pressure die casting conditions", Scripta Materialia, Pergamon, Vol. 53 No. 1, pp. 7-10.

Ishizaka, A. and Nemery, P. (2013), Multi-Criteria Decision Analysis: Methods and Software, John Wiley \& Sons.

Jolly, M. (2003), "Castings", in Milne, I., Ritchie, R.O. and Bhushan L. Karihaloo (Eds.), Comprehensive Structural Integrity, Elsevier, Oxford. 
Kabir, G., Sadiq, R. and Tesfamariam, S. (2014), “A review of multi-criteria decision-making methods for infrastructure management", Structure and Infrastructure Engineering, Taylor \& Francis, Vol. 10 No. 9, pp. 1176-1210.

Liu, H.-C., Ren, M.-L., Wu, J. and Lin, Q.-L. (2014), “An interval 2-tuple linguistic MCDM method for robot evaluation and selection", International Journal of Production Research, Taylor \& Francis, Vol. 52 No. 10, pp. 2867-2880.

"MakeItFrom.com: Material Properties Database". (n.d.)., available at: https://www.makeitfrom.com/.

NASA. (2015), NASA Cost Estimating Handbook, Version 4.0, Washington, D.C.

North American Die Casting Association. (2018), NADCA Product Specification Standards for Die Casting.

“Online Materials Information Resource - MatWeb”. (n.d.). , available at: http://www.matweb.com/.

Ou-Yang, C. and Lin, T.S. (1997), "Developing an integrated framework for feature-based early manufacturing cost estimation", The International Journal of Advanced Manufacturing Technology, Springer-Verlag, Vol. 13 No. 9, pp. 618-629.

Pagone, E., Papanikolaou, M., Salonitis, K. and Jolly, M. (2018), "Metal Casting Energy Efficient Metrics for Material Selection of Automotive Parts", International Conference on Sustainable Design and Manufacturing, pp. 290-303.

Pagone, E., Salonitis, K. and Jolly, M. (2018), "Energy and material efficiency metrics in foundries", Procedia Manufacturing, Vol. 21, pp. 421-428.

Pagone, E., Salonitis, K. and Jolly, M. (2019), "Energy-Efficient Casting Processes", Innovations in Manufacturing for Sustainability, Springer, pp. 77-98.

Quested, P.N., Dinsdale, A.T., Robinson, J.A., Mills, K.C. and Hunt, J.D. (2000), The Prediction of the Thermophysical Properties and the Solidification of Commercial Alloys, National Physical Laboratory, Teddington.

Schrader, G.F. and Elshennawy, A.K. (2000), Manufacturing Processes and Materials, Society of Manufacturing Engineers.

Shuaib, M., Seevers, D., Zhang, X., Badurdeen, F., Rouch, K.E. and Jawahir, I.S. (2014), "Product Sustainability Index (ProdSI) A Metrics-based Framework to Evaluate the Total Life Cycle Sustainability of Manufactured Products”, Journal of Industrial Ecology, Vol. 18 No. 4, pp. 491-507.

Stam, A. and Kuula, M. (1991), "Selecting a flexible manufacturing system using multiple criteria analysis", The International Journal of Production Research, Taylor \& Francis, Vol. 29 No. 4, pp. 803-820.

Triantaphyllou, E., Shu, B., Sanchez, S.N. and Ray, T. (1999), "Multi-criteria decision making: an operations research approach", Encyclopedia of Electrical and Electronics Engineering, Wiley, New York, pp. 175-186.

Tseng, M.-L., Wu, K.-J., Hu, J. and Wang, C.-H. (2018), "Decision-making model for sustainable supply chain finance under uncertainties", International Journal of Production Economics, Elsevier, Vol. 205, pp. 30-36.

Valencia, J.J. and Yu, K.O. (2002), “Thermophysical properties”, in Yu, K.O. (Ed.), Modeling for Casting 
and Solidification Processing, CRC Press, pp. 189-238.

Vincent, F.Y. and Hu, K.-J. (2010), “An integrated fuzzy multi-criteria approach for the performance evaluation of multiple manufacturing plants", Computers \& Industrial Engineering, Elsevier, Vol. 58 No. 2, pp. 269-277.

World Commission on Environment and Development. (1987), Our Common Future, Oxford University Press, Oxford.

Zardari, N.H., Ahmed, K., Shirazi, S.M. and Yusop, Z. Bin. (2015), Weighting Methods and Their Effects on Multi-Criteria Decision Making Model Outcomes in Water Resources Management, Springer International Publishing, Cham, available at:https://doi.org/10.1007/978-3-319-12586-2. 
2020-04-23

\section{Multi-criteria decision-making for the life cycle of sustainable high pressure die casting products}

Pagone, Emanuele

Inderscience

Pagone E, Papanikolaou M, Salonitis K, Jolly M. (2020) Multi-criteria decision-making for the life cycle of sustainable high pressure die casting products. International Journal of Sustainable Manufacturing, Volume 4, Issues 2-4, April 2020, pp. 101-120

https://doi.org/10.1504/IJSM.2020.107140

Downloaded from Cranfield Library Services E-Repository 